\title{
The Uncanny As a Sense of Presence in MX
}

\author{
Kenneth Feinstein \\ Sunway University \\ Centre for Research-Creation in Digital Media \\ No. 5, Jalan Universiti \\ 47500 Bandar Sunway Selangor Darul Ehsan \\ Kuala Lumpur, Malaysia \\ kenf@sunway.edu.my
}

\begin{abstract}
This paper looks at Freud's essay on the uncanny as to understand how it is used in media art. It first analyses Freud's concept of the uncanny, then looks at how this idea has changed in art and philosophy. From there it looks at how the uncanny has become a central part of much of modern and contemporary art. It also looks at part of media practise that doesn't use the uncanny and why. Form there uses the work of the Centre for Research-Creation in Digital Media as a case study in how different forms of mixed reality media use or do not use the uncanny as a form of communication. Finally asking, how does a relationship with the uncanny define how we create narratives in different media.
\end{abstract}

Media art. Mixed reality. Uncanny. Montage. Post-modern theory.

\section{INTRODUCTION}

Since the creation of photography and the technical image, how we interact with the image has vastly changed. It moved from an interpretation of the real to its manifestation. He we react to such work has been reflective on this. As well as how we have developed an artistic language to understand it. As this language has developed how we relate to the work has evolved. What is of interest here is how we have used certain methods to create new forms of imagery and how they reflect differing ways of seeing ourselves. How has the image has become more narrative and how that images in time have demanded a different relationship between the image and the viewer. Where we used to see the image through the language of the tableaux vivant as having significance because of its distance from the viewer, no we are in a situation where we interpret works by how they are in relation to us. As such we can say that there is the classical relation of art and post technical image relationship. In the former we have the idea of the distance of the viewer to the image, where the latter is centred on this direct relationship. To understand how both these directions work we need to look at how works develop a sense of the uncanny as a communicative tool. To do this let's first take a look at how Sigmund Freud developed the idea of the uncanny and its effects.
In his essay on the uncanny Freud talks about the uncanny as an effect. It is how we react to a situation as a much as the situation itself. He starts his essay by going over different definitions of the uncanny from different languages trying to find a commonality. But of course, settles back into the German unheimlich, the familiar. As he goes through the idea of what the uncanny is and its effect, he moved between the words heimlich and unheimlich. He recognises that the familiar can be as uncanny as the new. "We can only say that what is novel can easily become frightening and uncanny; some new things are frightening but not by any means all. Something has to be added to what is novel and unfamiliar to make it uncanny" (Freud et al. 2003). Freud explains that the effect of the uncanny as fear and an unsettledness caused by making the familiar unfamiliar. From there his question is how it is created and in what circumstances does it exist. Once we understand that we can look at how the uncanny can and is used as an aesthetic tool in the making of media art.

\section{THE UNCANNY EFFECT}

As Freud looks at what is the uncanny effect his main contention is that it produces fear and disorientation. This is why he goes into an analysis of E. T. A. Hoffman's The Sand-man. This disorientation is the unsettling of the self in relation to understanding world as beyond the self. For 
Freud, the conception of the self is still very grounded in a Cartesian idea of the relation of the self to the world. (Deleuze 2001) Disorientation and fear is created by the confrontation of the Cartesian ideal to the Real. It is when one has to face the World as that which is beyond ourselves that such feelings happen. We see a similar situation in Kant's sublime were facing the sublime causes terror as much as ecstasy. Both Freud and Kant come from a time where the confrontation of the self to the other was seen as a rare and unusual occurrence. As Freud says the uncanny is caused from the familiar becoming the unfamiliar. As such a greater familiarity with the uncanny itself will change the nature of our relationship to it. We can see in his literary analysis that it is the sense of self that defines it. The uncanny can be seen as a way of reacting to events where the other comes before the ego. It is when events happen outside of direct control of the self that terror is invoked. Otherness is seen as reflective of the self. If events require facing otherness as real this is when the uncanny is invoked. So that anything that interrupts the world of the ego can invoke the uncanny. "[A]n uncanny effect is often and easily produced by effacing the distinction between imagination and reality, such as when something that we have hitherto regarded as imaginary appears before us in reality" (Freud et al. 2003). Fear and discomfort occur through this confrontation of the imaginative and the real. In a work like The Sand-man the uncanny effect happens because of the juxtaposition of what Nathanial believes to be real, the presence of the sandman, in the world. The uncanny is an effect, it only exists through how one encounters this what can be seem the real and the imaginative in a way where both are treated as equally real. How this affects us could be the terror of Hoffman and Freud, or it could be method for us to see the world and the forces behind it in a different way. It can be seen as a vehicle for facing the Other.

For Freud a relationship to otherness is only understood in relation to how it determines the self. He uses the story The Sand-man as an example of how that which is not the self is dangerous. The centring way from the self towards facing otherness is seen a loss of Ego and destructive. He interprets the story as centring on the castration complex. It is the loss of power by the Ego when confronted by the Other that causes this. It is an idea where for the Other to have an active part in an event or situation it means a loss for the Ego. It is a reading where the Ego must have control and thus supremacy over the being in the world. As such it denies being-with-theworld as a valid function. It is a view of Being in the world where the Other must be inferior. It is an ideological construct, which in the end tries to deny the phenological as a way of defining the transcendental. So that anything that disrupts the supremacy of the self as Being has to be a source of terror.

Central to the terror found in Freud's uncanny and also Kant's sublime is a facing of Otherness as something that is bigger than us and as a manifestation of the Real. Where in the Cartesian cogito whatever is outside of the self only exists as much as it is recognised by the self, the uncanny and the sublime are seen as events that go beyond confirmation through the enunciation of thought.

Further in his essay as Freud tries to explain why some works possess the uncanny while others don't, he talks about Fairy-tales. He states, "Fairy-tales quite frankly adopt the animistic standpoint of the omnipotence of thoughts and wishes, and yet I cannot think of any genuine fairy-story which has anything un-canny about it." (Freud et al. 2003) He goes on to explain that such stories create a world where what we would normally consider uncanny is not, because it is part of that world. As the story world is one that is wholly imaginative, there is no place for it to confront the real. Within its world all of it is equally real. As a reader or viewer, we accept what would be uncanny in our world as normal in that world. When makes a work that is all encompassing and doesn't bring in the Real, there is no room for the uncanny. In current media we see this in space operas, the Marvel Universe and video games like Final Fantasy.

Freud first published The Uncanny in 1919. While subsequent writers have drawn very strong parallels between Freud's theories and cinema and visual art, Freud himself did not engage in such thinking (Sklarew 1999). Where the contemporary developments in visual arts were utilising aspects of what Freud described as the uncanny. This seems to have been lost on him. His use of art in his works tends towards literature. Works like Hoffmann's The Sand-man are experienced by the reader as internal monologue. This suites Freud's theories in a way that visual art does not. It allows the world to remain only a reflection of our psyche. From this we can see why he never engaged with the new developments of art and theory that explored relationships of otherness as an active agent. The idea of our being as formed by a nonlinear relationship with otherness that is equal to the self was beyond Freudian thought. In the end he remained Cartesian in his thought.

\section{THE UNCANNY EFFECT IN VISUAL ARTS}

In using the word unheimlich as the uncanny, Freud also recognises that given the context the familiar (Heimlich) can become the uncanny too. That it is the effect created by the situation that opens up the uncanny to us. It is an effect, trope in the end. Artists have utilised this idea of the familiar as uncanny as a way of having us read meaning into their montages. 
We can find this in film montage where different images are joined together to create a new meaning. Whenever a film has a shot and a reaction shot, we see this in action. Comedy is based on how we disrupt the familiar turning it into the uncanny. In fine art we see this in the use of montage.

Artists such as the Dadaists started to create a new visual language, montage, based on the unlikely juxtapositions of desperate images from desperate sources. The form of meaning developed by this methodology is one where 'the distinction between imagination and reality' are consciously blurred to create an uncanny effect. A distinction should be made between montage and collage. Although a montage can be referred to as a collage, collages also include image that use a variety of source images to create a seamless image. One that hides its sources. An example would be Henry Peach Robinson's Fading Away (1858). This was a photocollage made to represent the last moments of a young girl dying of tuberculosis. We are not mean meant to see this image as a single naturalistic scene, not as a composite. We can read this image as a forerunner to modern cinematic special effects. The photo montage on the other hand, is conceived as using the juxtaposition of desperate images to create a new visual reality. Its form is one where we are expected to be aware that what we are looking at is derived from multiple sources. That the new image created has a different meaning than what was found in the original sources. It was first meant as a way of creating a cultural and political critique of European socialites. We find this practise develop across art movements of various political views all trying to come to terms with industrialism, the aftermath of the First World War, the new growing nationalisms and the reality of the irrational in our world (Hughes 1991).

With Surrealism's influence, Freud's ideas of the uncanny were incorporated into montage in ways very different from Freud's intent. It doesn't matter if this is done through imaginative images (paintings and drawings) or images from reality (photography and film) the uncanny becomes a vehicle for addressing a relationship to otherness. If the image can be seen as a singular being or idea, it only exists through its constitute elements which are other to it. It is made up of the which is other to it. Its' meaning exists in debt to the meanings of the prior images and how they enter into dialog with each other. This reflects Emmanuel Lévinas' idea the preoriginal and our debt to Otherness (Lévinas 1998) as well as Martin Buber's ground of the individual in the world through the context of the IYou and I-It relationships (Buber and Kaufmann 1970). For Buber and Lévinas we can only exist in the world by facing the real, that which is beyond us. It is through how we interact with otherness that defines how we live in the world. Buber's I-You formulation is founded on the idea that self as being is created through how we encounter others as equals. This is exemplified by the dialog. It is through our coming into relation with the other that allows us to become fully human. Lévinas goes further to say that we owe our existence to otherness as it is prior to us and forms us. This leads to a demand on us to be responsible to the other as it is responsible for our being. In both cases these philosophers are bringing us away from a Cartesian belief that the cogito is of greater import than physical world and that only my thought can truly be real. Instead, we are become being living in and for the world. Our responsibility is to others in a way foreign to Descartes. We are expected to face others in the world as being as real as we are and not just signifiers used to create meaning. We live in a world where not everything can be reduced to meaning and reason. Experience in and of itself becomes significant. It becomes how to experience our relationship with and in the world. The nature of how the montage world reflects this world view. Montage becomes a method of coming to terms with the irrational nature of the world we live in. As montage expresses a philosophical view as a methodology it develops anaesthetic. We find this aesthetic not just in works of photomontage artist

like John Heartfield, but also in the paintings of René Magritte. As different media are incorporated into art, we find that the montage aesthetic has become a force within art and especially media. Works that are based on our relationship with each other, ones that are conscious of what visual elements are referring to tend towards this montage/uncanny aesthetic. If we look at works from Robert Rauschenberg, to Hans Haacke, Isaac Julian or Charles Lim we see this aesthetic in play. It has become a major form of how create experiential work.

At the same time we need to see that other forms of technology has made it easier to create visual works that are outside of this aesthetic. When Freud talked about folk-tales he said that they do not produce the uncanny because they create a world where the what would seem to be uncanny to us is normal. As stated earlier we see this in gaming, certain film franchises and some theatrical events. Even though we tend to think about media based art as possessing the uncanny as its main form of aesthetic. Where we can say that the uncanny/montage aesthetic relates to being conversational and experiential, these other works tend towards being immersive. They are about placing you in an environment that is distinctly different from the real. They create new forms of reality for the viewer to experience. The suspension of disbelief and desire to immerse oneself into a different world is what gives these forms their power. I would like to look at how these two tendencies are used to the creation of contemporary media works. 


\section{CRCDM: A CASE STUDY}

In order do this I would like to look at the work done by the Centre for Research-Creation in Digital Media (CRCDM) at Sunway University in Kuala Lumpur Malaysia. As a member of the centre, I will be analysing my own work as well as my colleagues. The centre has created a variety of works of digital media. This has included fine art projects, works of digital heritage of Malaysian culture, as well as digital museums and games. The works have included mixed reality, augmented reality, multiscreen cinema, and virtual reality. As with most contemporary media the narrative structure is fundamental to all these projects. What is interesting is how that narrative is presents itself in relation to this idea of the uncanny and the montage aesthetic. We will look a series of works from various members of the centre in. order to see how the uncanny is or isn't utilised in them. We are not making any judgment on the aesthetic value of the work by making these judgements rather it is my intension to make it easier to see how understand the nature of the way these various technologies present meaning to us. Within these projects we see the use of mixed realty, augmented reality and virtual reality as well as the incorporation of artefacts into different works.

\subsection{The projects}

Looking at the works in question here we can look at them from a variety of ways. There are those employ physical artefacts, those that only use virtual artefacts. There are works that are academically focused, ones that are more artistic and metaphorical and projects that are narrative uses of purely virtual environments. Of course, most projects will cross over these categories. As time-based works they all have a narrative element to them. And we will look at how the uncanny is used within that narrative process. Most of these works relate back to the real world, but in very different ways. It is in those differences that we will how the uncanny is or is not used.

Park Bench Sojourn is a work developed by Matthew Sansom. This work is primarily an audio work. It was originally conceived to allow the audience to download a soundscape and listen to it in a different location. Sansom's idea was to have people remove themselves from the normal world and take the time experience the otherness of a different location. With the CRCDM he has further developed version that incorporate Virtual Reality. In these versions the user chooses an environment, which they hear and see. While the audio is a recording from a real environment the images do not have to be. In some cases, they are purely artificial recreations of spaces imagined from the sound, in other versions they are real time videos taken at the same time as the soundscape. In both the mobile and the gallery version the park bench is the primary artefact that locates the work. In all versions one is expected to sit in the bench, and it becomes the focus of the experience.

While the work is meant to remove one from their present space, this only has meaning because one is aware of that removal. The awareness of what we are closing ourselves off from is fundamental to the work. As a public artwork where I choose where to experience this soundscape, it the experience to the user to place in time and space. As such we understand a relationship to what we are removing ourselves from as much as what we are placing ourselves into. This is a utilisation of an uncanny aesthetic where this juxtaposition of disparate elements is on a more metaphorical level rather than physical. As a purely audio piece we choose where and when to experience it. Meaning that we are responsible for the uncanny juxtaposition elements. The removal of a traditional narrative also allows us to understand our experience as removal from the world into a zone of being-with the experience before us. What is interesting here is that the work is meant to have a soothing effect on the user while staying within an uncanny aesthetic. As we said earlier for Freud the uncanny invokes terror and here it is used to do the opposite.

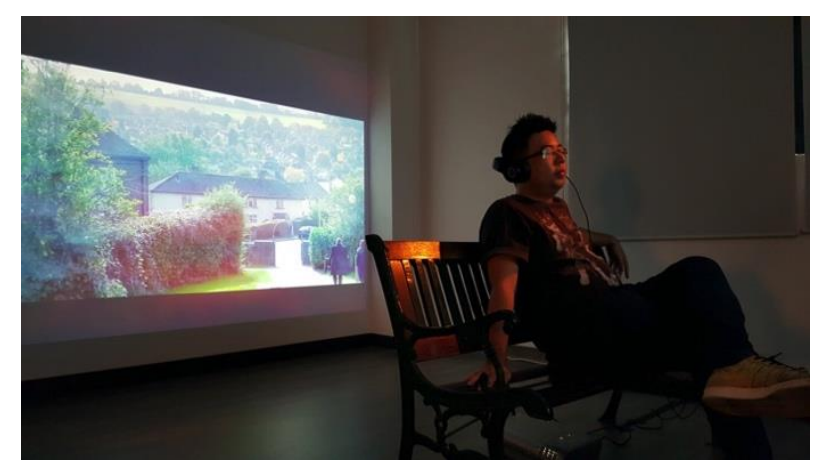

Figure 1: User experiencing Park Bench Sojourns at the exhibition Transmedia: Stories in Media, Kuala Lumpur, Malaysia, 2017. Courtesy of Matthew Sansom.

The tension between the mobile version and the gallery version presents some interesting questions. In a gallery format we choose an audio-visual environment and become immersed in it. The interference of the real world is eliminated. If we are using VR headsets the outside world becomes more remote. Our awareness of the outside world and our physical relationship to it is eliminated. When we put on the headset, we enter a complete world. What we see and hear is unified into a totality. This is especially true within a gallery setting. The gallery is already a removal from daily life and now this work is a removal from that. The nature of the uncanny is erased even as it was an original force behind the concept of the work. What gives the mobile version an uncanny effect is the contract between a feeling of immersion and being in the world. While in the gallery setting the immersive nature of the work is all 
that is felt, foregrounding the emotional aspect of the work in a different way. As we look at the difference between the two works, we see how VR technology moves us away from an uncanny feeling into one of the totality of immersion.

Another work using a physical artefact as focal point to the work is Post Box Cinema. This work was created by Kenneth Feinstein. The piece is the recreation of a Malaysian post box projects a German Romantic style video of the Swiss Alps as its shadow. The intention of the work is present a relationship between modern capitalist thought and the Romantic nostalgia found in the works of Fredrick Casper David and Goethe. It juxtaposes the image of a post box with that of the shadow image.

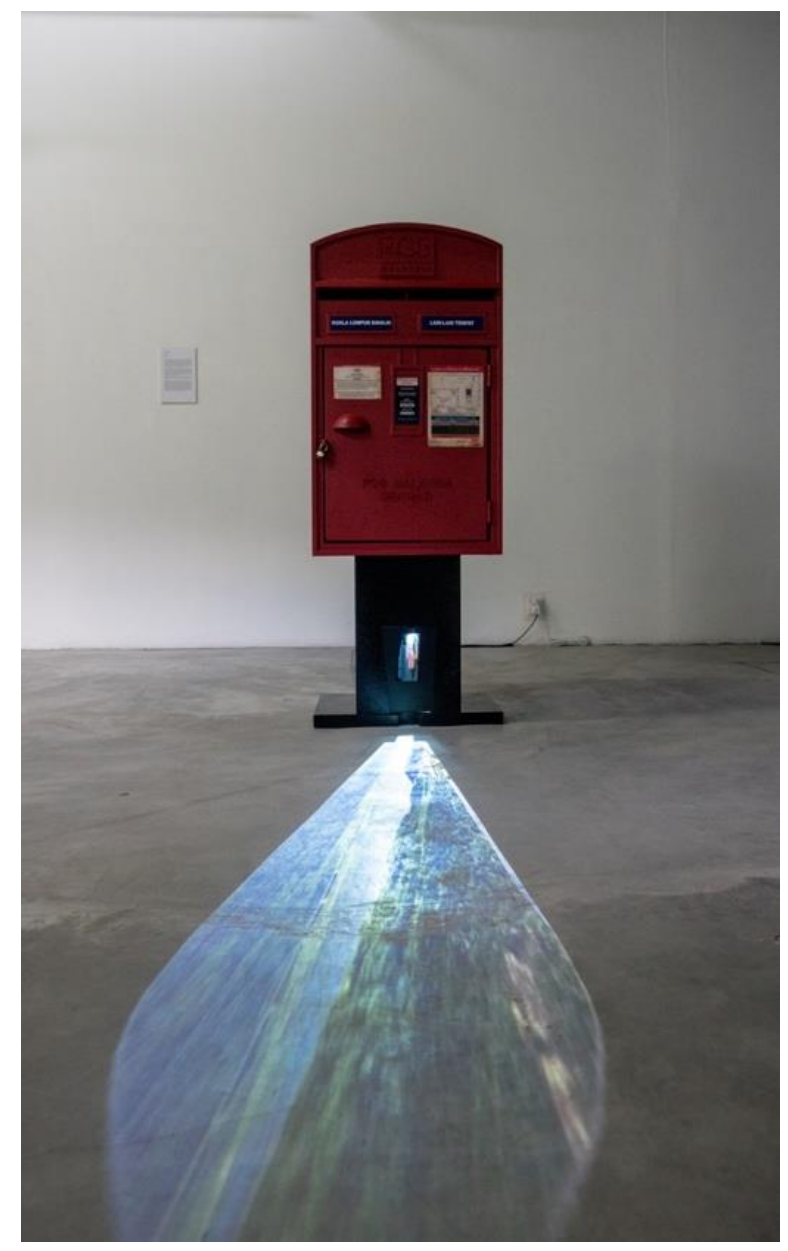

Figure 2: Post Box Cinema installed in the exhibition Paralogical Machines at Wei-Ling Contemporary, Kuala Lumpur, Malaysia, 2019. Courtesy of Ken Feinstein.

In this work the post box symbolises the modern world. It was chosen as a symbol of modernism because the postal system was conceived of as an equal and democratic way for citizens to petition the government. It is the only form of communication that is always public. By contrast, the Romantic landscape speaks to the idea of an idealised landed aristocracy. A type of life that is not democratic or speaks of equality. The concept of the work is to depict how the ideal of the landed aristocracy is still active within the modern capitalist ideal. We see this on how the newly wealthy tend to buy farms as retreats from the city and their work. These supposed idylls are where they can live life as if they were the old landed barons, but without the responsibilities of the aristocracy. We can see this reflected in how these former farms have been rebuilt to reflect and ideal grounded in a Romantic sense of landscape. Many of these generally nonworking farms have been relandscaped so that the view from the main house looks like a traditional landscape painting. The image of an estate becomes more important than the reality of a working farm. The work emphasises how our relationship to nature has moved away from direct experience into an imaginative one. Where the ideal is becomes more important than the real.

This project was very consciously developed from this montage aesthetic as it developed from a previous series of photomontages. It uses the shadow as a metaphorical device to represent a hidden ideology active within the master image, in this case the post box. It developed away from photomontage and towards physical objects to heighten the sense of the uncanny and so that the physicality of the object would bring it into a more direct relationship with the viewer. As an object in the world we interact with it as a thing. We are able to enter into an I-You dialog more directly. The intention of the work is that it would be placed in the same type of public spaces where one would find a post box, encountering the viewer outside of an art context. By bringing the object into the world the uncanny effect is enhanced because the unexpectedness of the object and its function. Aesthetically and conceptually this work is based on creating an intimate relationship between the viewer and the object based on the idea of being-with otherness as dialog.

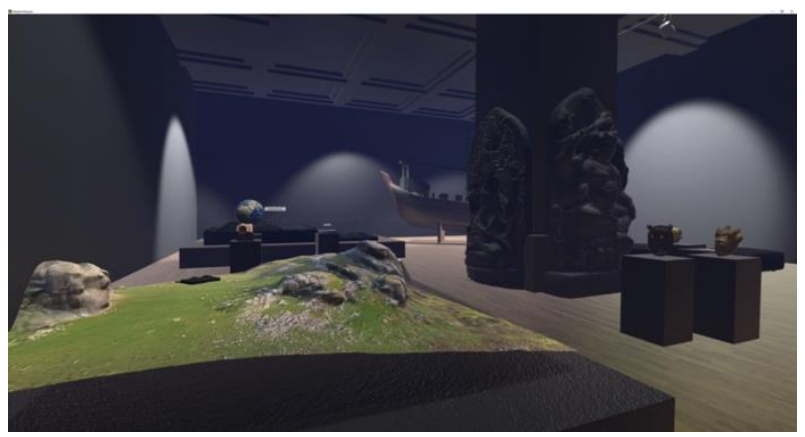

Figure 3: Early prototype of a Virtual Heritage Museum, 2017. Courtesy of See Zi Siang.

The idea of a virtual heritage museum is an interesting project because it is using VR as a way to experience objects and folklore in a way that is not normally available to the public in physical spaces. This is an ongoing and developing work at the CRCDM. Originally conceived of by the 
Centre's Director Harold Thwaites, it has utilised the talents of most of the centre in its ongoing development. A central aspect of this work is presenting the intangible context of traditional museum artefacts. Such a museum is supposed to allow visitors to see the development of artefacts as they are created, hear the stories that are tied to the artefact and virtually touch the works. These are all aspects of cultural heritage that have been difficult to present in a traditional museum. As museum visitors we are aware that most artefacts in museums are in vitrines or behind glass. Visitors can only observe these objects at a distance. In relation to cultural heritage this remove alienates us the objects and removes any context from the work. One can appreciate a Mah Meri mask from a distance of a meter or two but cannot see the chisel strokes that made the mask. Traditionally one can read a text that gives a summary of the tales associated with the work, but that is very different from hearing it being told to me by the carver or an indigenous storyteller.

In this project objects have been collected specifically for the virtual museum as well as objects from other collections have been incorporated into it. In the former case, one of the researchers, Delas Santano has worked with indigenous artisans to document the process of making an artefact, in this case a mask, and interviewed them for the stories associated with the object for another project. The objects and tales will be incorporated into the virtual museum. In the latter case other research centres or museums have given permission to create $360^{\circ}$ scans of the objects for a collected database and to be placed into the museum. In such cases, only the artefact is available and not the richer contextual information.

Within the concept of the work is the idea of the viewer being able to come closer to the objects. They are not there to create an unfamiliar feeling in the viewer. It is not intended for one to see this as exotic or other, rather the concept is the opposite, to make the objects and their context more familiar to us. The choice of VR in this project was expressly because it does not possess the uncanny. It is the immersive and inclusive nature of the medium that lent itself to the project. The idea that this medium allows for exploration and interaction is central to the concept of the virtual museum.

Lastly, I would like to look at The Hainan Boatbuilder of Pangkor Island project. This is a large on-going work. It is an investigation into a disappearing art form the making of these large wooden boats. Approximately, 65 to 120 tonnes these boats are made by hand by craftsmen working from experience and memory. The designs are not blueprinted and are built from the knowledge ang memory of the master builder. In terms of heritage, the knowledge of the builder and the object built represent Malaysian heritage.

As a project the centre wanted to preserve both aspects of heritage present in the making of a boat. They approached the collecting of materials as a form of database for multimedia presentation. Because the experiences of $\mathrm{Mr}$ Goh, the last master boatbuilder, was as important as the finished object, the boat, the nature and purpose of how the data was collect is different from traditional museum science.

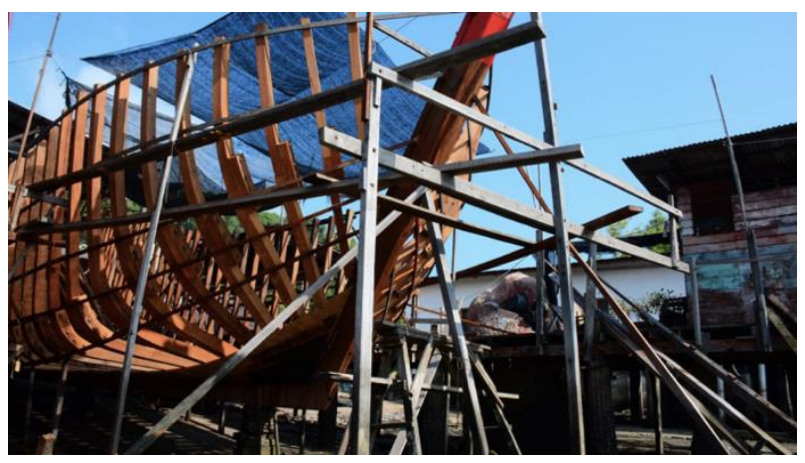

Figure 4: Image from the Hainan Boatbuilder of Pangkor Island, 2017. Courtesy of Delas Santano.

The team's idea of data collection was as much based in documentary film and photography as it was in artefact collection or traditional ethnography. Where ethnographic film tends towards being observational and removed from what is being recorded, the team here conceptualised the project as one which creates presence for the viewer. $360^{\circ}$ video, aerial drones, and conventional documentary style footage was combined with 3D models to allow the team to create different forms of display. This material has been used in a version of the VR museum, in AR enhanced publications and gallery exhibitions. Central to all of these forms of display is how the material was conceived and created. The work was conceived to create a sense of presence in the viewer, they are put into a relationship of being-with Mr Goh and his workers. Viewers are meant to feel included in the process as it unfolds around them. It is not intended to create a feeling of the uncanny as that would be alienating in this situation. Rather it is intended to make the viewer face Mr Goh and his colleagues as real people. We do not turn them into symbols of disappearing culture, we are asked to face them as the real people they are. The work presents us with the other as real, as that which we are responsible for in how we interact with them. It is the intimacy of the material that brings forward their reality and allow is to share it. What is uniquely interesting in this work is the importance of the conceptual model and how it allows for a variety of different presentations. So that a narrative approach was put into the collection of the material instead of after the fact. 


\section{CONCLUSIONS}

As we have seen in Freud's essay The Uncanny, how we experience the unfamiliar is based on the context in which we experience the event. Further, that when actions or works are made to interact with the real, the power of the uncanny is unleashed to create meaning. Artists have created a method that utilises the juxtaposition of differing elements from diverse sources to create works that redefine how we see the world. The aesthetic created by this montage is one where the fragmentary is seen as active in our world. Their works are one where the differing elements are in dialog with each other and the viewer, creating a new relationship between work and viewer. The nature of this relationship is one that Buber called IYou and Lévinas would say is being-with the other as a face-to-face encounter. Both of them are talking about a relationship where the other is confronted in their actuality and not just as an object of symbolic language. Central to this aesthetic is that the works must encounter the real in some manner to allow the uncanny to exist.

At the same time Freud acknowledged that some works cannot possess the uncanny because they create a fully formed world that excludes the real. These alternate realities can be used to comment on the real, but what would seem uncanny in the real world submit to the logic of these worlds. We can see where this direction in media work tends towards the video games, VR and can be found in cinema too. What is significant is that with new forms of media technology the possibility of embedding the dialogic I-You form is possible in such works. Where theatre, cinema and literature have created these wholly formed worlds, they tended to present these worlds as distant from the viewer. With immersive and interactive media, given the correct sensibility it's possible to create works that do not possess the uncanny, but still present that same relationship to otherness. We are able to create forms of dialogic presence that allow the viewer to feel a part of the experience instead of alienating them. This is not inherent to the form, there are plenty of immersive works that alienate the viewer or where the sense of presence is minimal. To do this the creator has to be conscious of bringing this dialog with otherness forward. It has to be understood in the planning and creation of the work and cannot just be assumed to be there. We have looked at the works of the Centre for Research-Creation in Digital Media as a case study of practitioners who have developed works of both forms, possessing the uncanny and not, but who have kept the idea of presenting the other as a non-thematizable other who we face as equals. In their heritage and artistic work this aesthetic has been there. As such they are a good example of how we should think about how we develop new media works moving forward.

\section{REFERENCES}

Buber, M. and Kaufmann, W.A. (1970) I and Thou. New York: Scribner.

Deleuze, G. (2001) Dualism, Monism and Multiplicities (Desire-Pleasure-Jouissance). Contretemps: An Online Journal of Philosophy 2: 17.

Freud, S., McLintock, D. and Haughton, H. (2003) The Uncanny. New York: Penguin Books.

Hughes, R. (1991) The Shock of the New. New York: Knopf.

Lévinas E (1998) Entre Nous: On thinking-of-theother. New York: Columbia University Press.

Sklarew B (1999) Freud and Film: Encounters in the Weltgeist. Journal of the American Psychoanalytic Association 47(4): 1239-1248. 